\title{
Correction to: Municipal wastewater viral pollution in Saudi Arabia: effect of hot climate on COVID-19 disease spreading
}

\author{
Hadil M. Alahdal ${ }^{1} \cdot$ Fuad Ameen $^{2}\left(D \cdot\right.$ Sami AlYahya $^{3} \cdot$ Hana Sonbol $^{1} \cdot$ Anas Khan $^{4,5} \cdot$ Yousef Alsofayan $^{5}$. \\ Ahmed Alahmari ${ }^{5}$
}

Published online: 8 October 2021

() Springer-Verlag GmbH Germany, part of Springer Nature 2021

\section{Correction to: Environmental Science and Pollution Research https://doi.org/10.1007/s11356-021-14809-2}

Funding:

The authors extend their appreciation to the Deputyship for Research \& Innovation, Ministry of Education in Saudi Arabia for funding this research work through the project number (PNU-DRI-Targeted-20-028).

Publisher's note Springer Nature remains neutral with regard to jurisdictional claims in published maps and institutional affiliations.

The original article can be found online at https://doi.org/10.1007/ s11356-021-14809-2.

Fuad Ameen

fuadameen@ksu.edu.sa

1 Department of Biology, College of Science, Princess Nourah bint Abdulrahman University, Riyadh, Saudi Arabia

2 Department of Botany \& Microbiology, College of Science, King Saud University, Riyadh 11451, Saudi Arabia

3 National Center for Biotechnology, King Abdulaziz City for Science \& Technology, Riyadh, Saudi Arabia

4 Department of Emergency Medicine, College of Medicine, King Saud University, Riyadh, Saudi Arabia

5 Global Center for Mass Gatherings Medicine, Ministry of Health, P.O. Box 11461, Riyadh, Saudi Arabia 